\title{
CORRECTION
}

View Article Online

View Journal | View Issue

\section{Correction: Wound healing properties of hyaluronan derivatives bearing ferulate residues}

Cite this: J. Mater. Chem. B, 2015,

3, 7307

Giuseppe Valacchi, ${ }^{\text {ac }}$ Giorgio Grisci, ${ }^{b}$ Claudia Sticozzi, ${ }^{a}$ Yunsook Lim, ${ }^{c}$ Marco Paolino, ${ }^{\mathrm{b}}$ Germano Giuliani, ${ }^{\text {b }}$ Raniero Mendichi, ${ }^{d}$ Giuseppe Belmonte, ${ }^{a}$ Roberto Artusi, ${ }^{\text {e }}$ Andrea Zanardi, ${ }^{\text {e }}$ Paolo Garofalo, ${ }^{\text {e Gianluca Giorgi, }}$ Andrea Cappelli*b and Lucio Rovati ${ }^{\mathrm{e}}$

DOI: $10.1039 / c 5 t b 90126 j$

Correction for 'Wound healing properties of hyaluronan derivatives bearing ferulate residues' by www.rsc.org/MaterialsB Giuseppe Valacchi et al., J. Mater. Chem. B, 2015, DOI: 10.1039/c5tb00661a.

The authors regret an error in the spelling of the name of the 4 th author in the published article. The correct spelling is shown above.

The Royal Society of Chemistry apologises for these errors and any consequent inconvenience to authors and readers.

\footnotetext{
${ }^{a}$ Dipartimento di Scienze della Vita e Biotecnologie, Università degli Studi di Ferrara, Via Luigi Borsari 46, 44121 Ferrara, Italy. E-mail: giuseppe.valacchi@unife.it; Tel: +390532455482

${ }^{b}$ Dipartimento di Biotecnologie, Chimica e Farmacia and European Research Centre for Drug Discovery and Development, Università degli Studi di Siena, Via A. Moro 2, 53100 Siena, Italy. E-mail: andrea.cappelli@unisi.it; Tel: +390577234320

${ }^{c}$ Department of Food and Nutrition, Kyung Hee University, Seoul 130-701, Republic of Korea

${ }^{d}$ Istituto per lo Studio delle Macromolecole (CNR), Via E. Bassini 15, 20133 Milano, Italy

${ }^{e}$ Rottapharm Biotech, Via Valosa di Sopra 9, 20052 Monza, Italy
} 